\title{
BALNEÁRIO DA AMIZADE: LEVANTAMENTO DE AS- PECTOS AMBIENTAIS E ANÁLISE DOS CRITÉRIOS DE BALNEABILIDADE
}

Alessandra de Oliveira Alves Correia, Ana Beatriz Ribeiro Nobre, Elson Mendonca Felici, Daniel Ângelo Macena

Universidade do Oeste Paulista - UNOESTE, Presidente Prudente, SP. E-mail: ale.engenha@outlook.com

RESUMO - O Balneário da Amizade é considerado o manancial que pertence à bacia hidrográfica do alto curso do córrego do Limoeiro localizado entre os municípios de Presidente Prudente e Álvares Machado. O recurso hídrico é utilizado em casos emergenciais para abastecimento da rede de distribuição de água da Companhia do Saneamento Básico do Estado de São Paulo, sendo destinado à prática de esportes, lazer e turismo. Tendo em vista as características do local, objetivou-se levantar os aspectos ambientais da área de estudo e analisar a qualidade da água, visando à comparação dos resultados com a resolução do Conselho Nacional do Meio Ambiente. A metodologia baseou-se na norma Standard Methods for the Examination of Water \& Wastewater para as análises de coliformes termotolerantes e Escherichia coli dos cinco pontos de coleta e na caracterização da área de estudo. Levando em consideração o resultado do levantamento de aspectos ambientais, verificou-se que esses fatores interferiram na qualidade da água. Para avaliar a balneabilidade, considerou-se o ponto permitido para acesso aos banhistas. Ao comparar os resultados dos parâmetros microbiológicos, notou-se que a presença de 83.660 coliformes termotolerantes restringe o uso para contato primário no ponto 2 , sendo considerado impróprio aos banhistas, conforme descreve a Resolução CONAMA no 274/2000.

Palavras-chave: Qualidade da água. Recurso Hídrico. Microorganismos. Meio Ambiente.

BALNEÁRIO DA AMIZADE: SURVEYING ENVIRONMENTAL ASPECTS AND ANALYSIS OF BATHING CRITERIA

ABSTRACT - The Balneário da Amizade is considered the source that belongs to the hydrographic basin of the upper course of the Limoeiro stream located between the cities of Presidente 
Prudente and Álvares Machado. The water resource is used in emergency cases to supply the water distribution network of the Basic Sanitation Company of the State of São Paulo, being used for sports, leisure and tourism. In view of the characteristics of the place, the objective was to survey the environmental aspects of the study area and analyze the water quality, aiming at comparing the results with the resolution of the National Environmental Council. The methodology was based on the Standard Methods for the Examination of Water \& Wastewater standard for the analysis of thermotolerant coliforms and Escherichia coli from the five collection points and on the characterization of the study area. Taking into account the result of the survey of environmental aspects, it was found that these factors interfered with water quality. In order to assess bathing, the point allowed for access to bathers was considered. When comparing the results of microbiological parameters, it was noted that the presence of 83.660 thermotolerant coliforms restricts the use for primary contact in point 2 , being considered inappropriate for bathers, as described in CONAMA Resolution No. 274/2000.

Keywords: Water Quality. Water Resource. Microorganism. Environment.

\section{INTRODUÇÃO}

A água é um dos elementos indispensáveis para atender a necessidade humana e a sobrevivência de todos os organismos vivos. A água pode apresentar qualidades variáveis, dependendo do local, condições de sua origem e usos. $\mathrm{O}$ fornecimento de água doce de boa qualidade é indispensável para o desenvolvimento econômico, qualidade de vida das populações e para manutenção sustentável dos ciclos dos nutrientes no planeta (SELBORNE, 2001).

Segundo a Agência Nacional de Águas - ANA, "qualquer atividade humana que altere as condições naturais das águas é considerada um tipo de uso". Alguns exemplos de usos da água são a irrigação, abastecimento, indústria, hidroeletricidade e lazer. Diante de tantos usos, houve a necessidade de garantir que esses vários setores pudessem usufruir da água (BRASIL, 2019).

Para definir as diretrizes e políticas públicas voltadas para melhoria da oferta de água, surgiu a Lei federal no 9.433/1977 que instituiu a Política Nacional dos Recursos Hídricos - PNRH, apresentando como um dos instrumentos o enquadramento dos corpos de água em classes, segundo os usos preponderantes da água (BRASIL, 1997). Esse enquadramento visa garantir que as características da água estejam de acordo com sua utilização, sendo classificado desde o uso mais nobre, como consumo; até usos menos nobres, como limpeza e resfriamento de máquinas.

Além da PNRH, foi instituído pela Lei no 6.938/81, que dispõe sobre a Política Nacional do Meio Ambiente - PNMA, regulamentada pelo decreto no 99.274/1990, que o Conselho Nacional do Meio Ambiente - CONAMA, tem por atos a elaboração de resoluções, abordando diretrizes e normas técnicas, critérios e padrões relativos à proteção ambiental e ao uso sustentável dos recursos hídricos (BRASIL, 1981). 
Dentro das diversas resoluções elaboradas pelo CONAMA, foi abordada neste trabalho a Resolução no. 274/2000 que trata sobre os critérios de Balneabilidade em águas brasileiras. Para atender ao que dispõe, entende-se que o trabalho de campo é fundamental para que in loco possa ser observado as possíveis alterações, sendo demonstrado com os índices de qualidade da água, as condições impactantes ao ocorrer valores superiores aos estabelecidos nas devidas normas (SPERLING, 2005).

Sendo assim, como fonte de estudo para avaliação dos critérios de balneabilidade e levantamento dos aspectos ambientais, foi escolhido o local do Balneário da Amizade, após ser divulgado nas mídias que no ano de 2018, houve o rompimento de tubulações de esgoto após chuvas fortes. Dessa maneira, avaliar a qualidade da água se torna relevante em função do uso da qual é destinado.

Figura 1. Pontos de coleta de água.

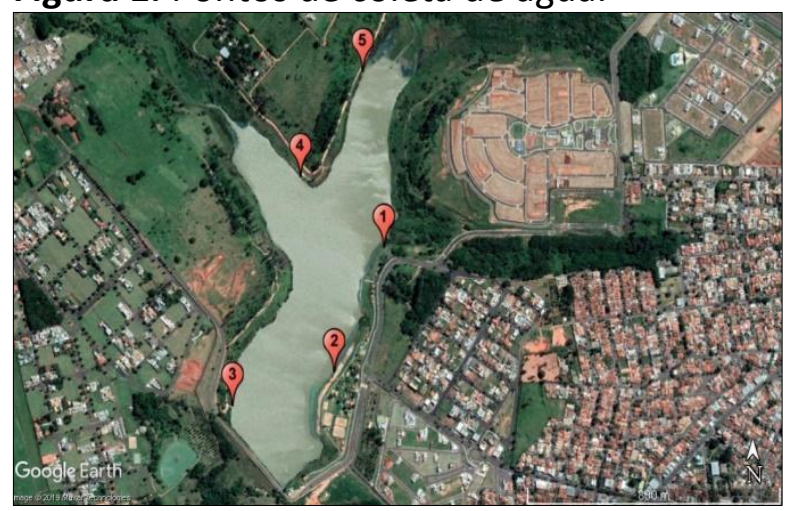

Fonte: (Google Earth, 2019).

\section{METODOLOGIA}

O estudo foi realizado no Balneário da Amizade, manancial pertencente à bacia hidrográfica do alto curso do córrego do Limoeiro, localizado entre os limites dos municípios de Presidente Prudente e Álvares Machado. Possui uma área de drenagem de aproximadamente $20 \mathrm{~km}^{2}$, correspondendo aproximadamente em $1 \%$ do total da bacia hidrográfica do Rio Santo Anastácio na qual está inserida. É uma represa artificial de $379.271 \mathrm{~m}^{2}$, com volume de $2.066 .000 \mathrm{~m}^{3}$ para armazenamento de água (SOARES; LEAL, 2015).

Os pontos de coleta foram marcados no software Google Earth, levando em consideração áreas que pudessem garantir representatividade e fácil acesso (figura 1), sendo demonstradas as respectivas coordenadas no quadro 1.

Quadro 1. Coordenados dos pontos de coleta.

\begin{tabular}{|c|c|c|}
\hline Pontos de coleta & \multicolumn{2}{|c|}{ Coordenadas } \\
\hline 1 & $22^{\circ} 06^{\prime} 06.69^{\prime \prime} \mathrm{S}$ & $51^{\circ} 26^{\prime} 32.81^{\prime \prime} \mathrm{O}$ \\
\hline 2 & $22^{\circ} 06^{\prime} 18.71^{\prime \prime} \mathrm{S}$ & $51^{\circ} 26^{\prime} 38.43^{\prime \prime} \mathrm{O}$ \\
\hline 3 & $22^{\circ} 06^{\prime} 21.92^{\prime \prime} \mathrm{S}$ & $51^{\circ} 26^{\prime} 49.91^{\prime \prime} \mathrm{O}$ \\
\hline 4 & $22^{\circ} 05^{\prime} 59.87^{\prime \prime} \mathrm{S}$ & $51^{\circ} 26^{\prime} 42.23^{\prime \prime} \mathrm{O}$ \\
\hline 5 & $22^{\circ} 05^{\prime} 49.78^{\prime \prime} \mathrm{S}$ & $51^{\circ} 26^{\prime} 35.20^{\prime \prime} \mathrm{O}$ \\
\hline
\end{tabular}

Fonte: (Autores, 2019). 
Figura 2. Local de estudo.

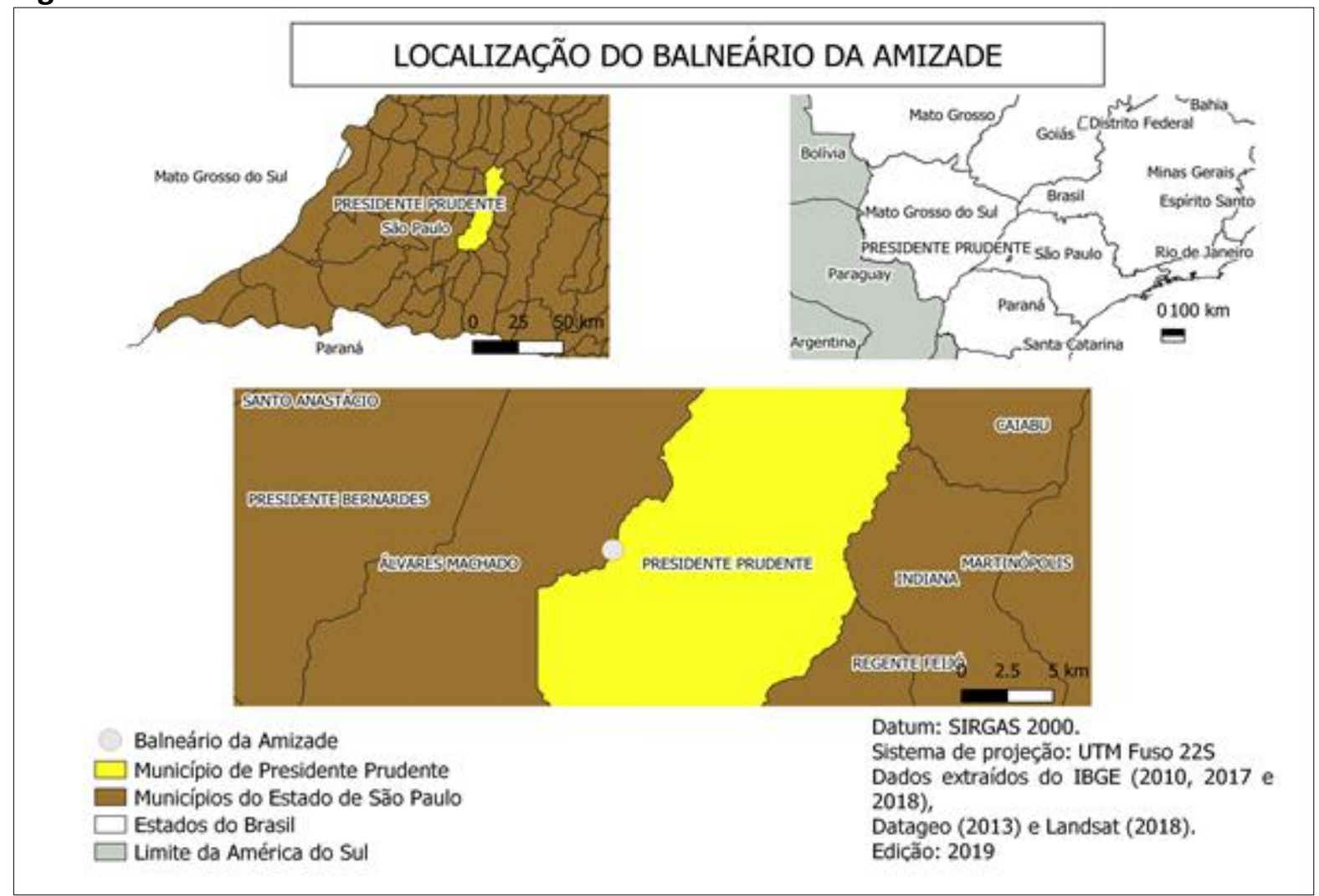

Fonte: (Autores, 2019).

As coletas foram realizadas durante os meses de abril a setembro de 2019, uma vez ao mês no período da manhã, com exceção de julho devido ao não funcionamento do laboratório no período de férias escolares. Buscou-se realizar as coletas na primeira semana do mês, entretanto os fatores climáticos afetaram os últimos meses de coleta. Os meses e os respectivos dias são demonstrados no quadro 2.

Quadro 2. Data das coletas.

\begin{tabular}{|c|c|c|c|c|c|}
\hline Mês & Abril & Maio & Junho & Agosto & Setembro \\
\hline Dia & 3 & 8 & 6 & 14 & 26 \\
\hline
\end{tabular}

Fonte: (Autores, 2019).

Para o procedimento das coletas de cada mês, primeiramente esterilizou-se os frascos de vidro e outros materiais na autoclave, para que a água pudesse ser coletada e posteriormente ser feito as análises microbiológicas, preparando o meio de cultura sempre um dia antes da data de cada coleta. Após a coleta das amostras, as mesmas fo- ram diretamente encaminhadas ao laboratório de química no bloco $Q$ da Universidade do Oeste Paulista - UNOESTE para os procedimentos de análises. Os locais das coletas podem ser evidenciados nas figuras 3,4,5,6 e 7 .

Figura 3. Ponto de coleta 1.

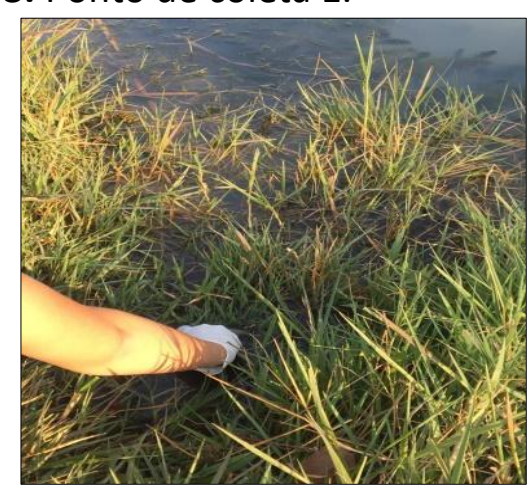

Fonte: (Autores, 2019). 
Figura 4. Ponto de coleta 2.

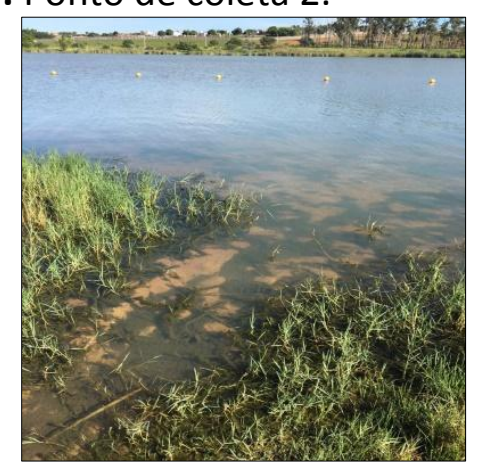

Fonte: (Autores, 2019).

Figura 5. Ponto de coleta 3.

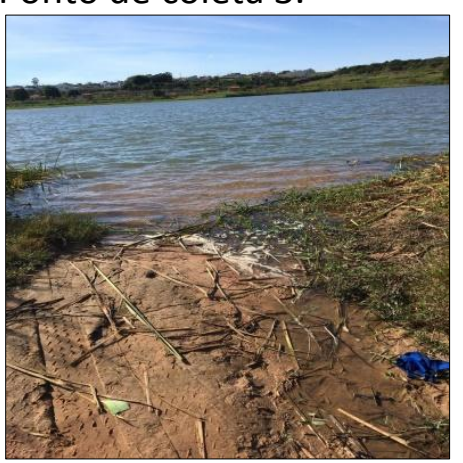

Fonte: (Autores, 2019).

Figura 6. Ponto de coleta 4.

Fonte: (Autores, 2019).
Figura 7. Ponto de coleta 5.

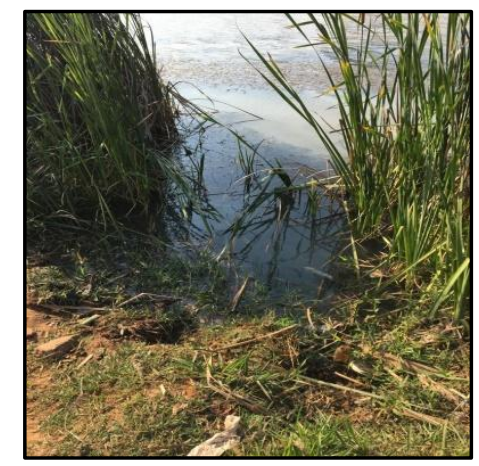

Fonte: (Autores, 2019).

Para obtenção dos resultados em relação aos coliformes termotolerantes e Escherichia coli, utilizou-se o "Standard Methods for the Examination of Water \& Wastewater - 20th/21th Edition" (AMERICAN PUBLIC HEALTH ASSOCITION, 2005) que é a metodologia já empregada pelo laboratório e utilizada como referência as normas técnicas da Companhia Ambiental do Estado de São Paulo - CETESB. Os parâmetros e respectivas frequências de análise, método empregado e referência é demonstrado no quadro 3.

Quadro 3. Metodologia das análises.

Fonte: (Standard Methods, 2005).

\begin{tabular}{|c|c|c|c|}
\hline Parâmetro & $\begin{array}{c}\text { Frequência das } \\
\text { análises }\end{array}$ & Método & Referência \\
\hline $\begin{array}{c}\text { Coliformes termo- } \\
\text { tolerantes e Esche- } \\
\text { richia coli }\end{array}$ & Mensal & $\begin{array}{c}\text { Membrana } \\
\text { filtrante }\end{array}$ & $\begin{array}{c}\text { SMWW, 21ạ } \\
\text { edição, Méto- } \\
\text { do 9222 D }\end{array}$ \\
\hline
\end{tabular}

Fonte: (Standard Methods, 2005).

O método membrana filtrante é uma técnica em que é possível identificar e quantificar micro-organismos presentes na água em meio de cultura utilizando ágar seletivo. Durante os procedimentos do método, reali- zou-se a diluição da amostra em 100 uL (limite de quantificação: $1 \mathrm{UFC} / 100 \mathrm{~mL}$ ), já que não sabia se as alíquotas de água passariam facilmente pela membrana filtrante. Assim, essa diluição ajudou a diminuir o tempo de 
análise sobre esse parâmetro e posteriormente, foi possível identificar com a contagem de colônias vermelhas - salmão (Coliformes termotolerantes) e colônias azuis pretas (E. coli).

Já o levantamento de aspectos ambientais foi elaborado com registros fotográficos nos dias de coleta.

\section{RESULTADOS E DISCUSSÕES}

\subsection{Levantamento de aspectos ambientais} da área de estudo

Apesar do investimento na infraestrutura do lado de Presidente Prudente, durante os meses de trabalho de campo, foram notadas alterações causadas pelo processo de expansão urbana conforme citado por Frois (2015). Alguns desses problemas levantados foram ausência de mata ciliar, descarte irregular de resíduos sólidos e a presença de animais em local de acesso para banhistas.

Já do lado do município de Álvares Machado, apesar de ser considerada uma área mais isolada, também foi observado com visitas in loco, impactos negativos decorrentes de ações antrópicas, principalmente intervenção em Áreas de Preservação Permanente - APP e descarte irregular de resíduos sólidos.

No primeiro contato com o local no mês de abril, no ponto 1 identificou-se a presença de taboa. Esse ponto se localiza próximo a um dos limites do manancial, e possui nessa região um afluente (figura 8 ).

Figura 8. Taboa próximo ao ponto 1.

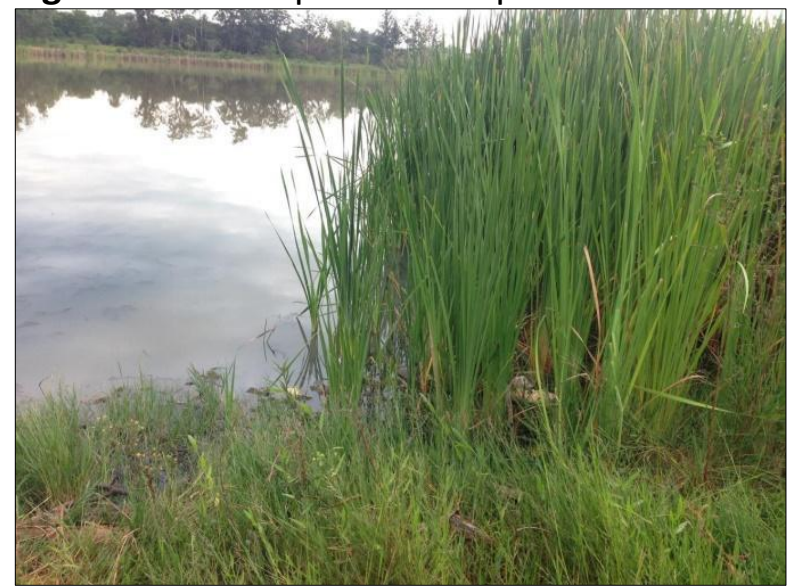

Fonte: (Autores, 2019).
A presença dessa macrófita conforme as figuras 9 e 10 foram pertinentes nas margens, ocorrendo de maneira significativa nos pontos 1 e 5.

Figura 9. Propagação da taboa no ponto 1.

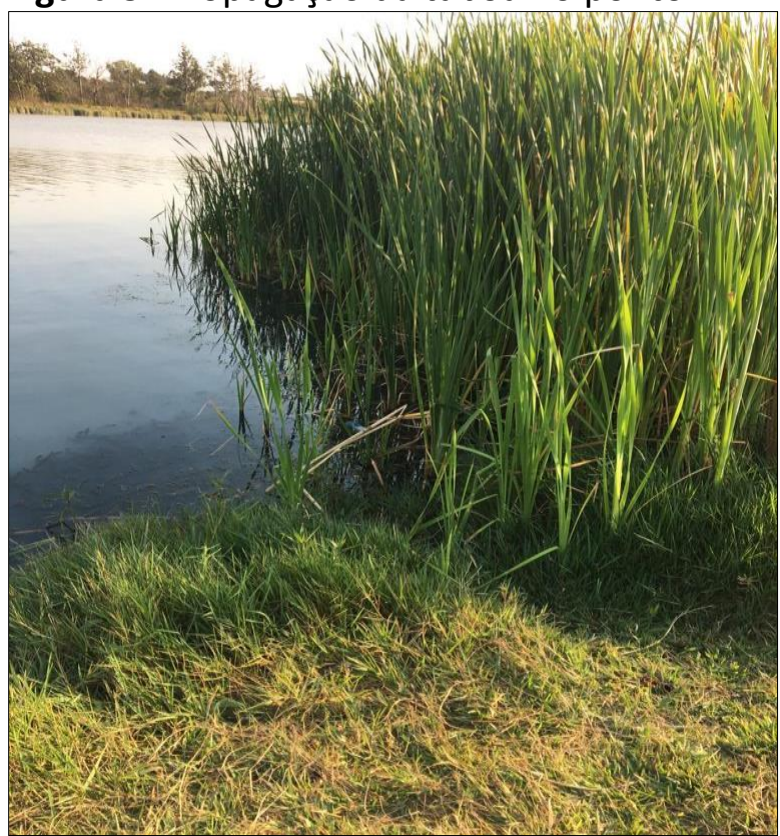

Fonte: (Autores, 2019).

Figura 10. Reconhecimento da taboa no ponto 5 .

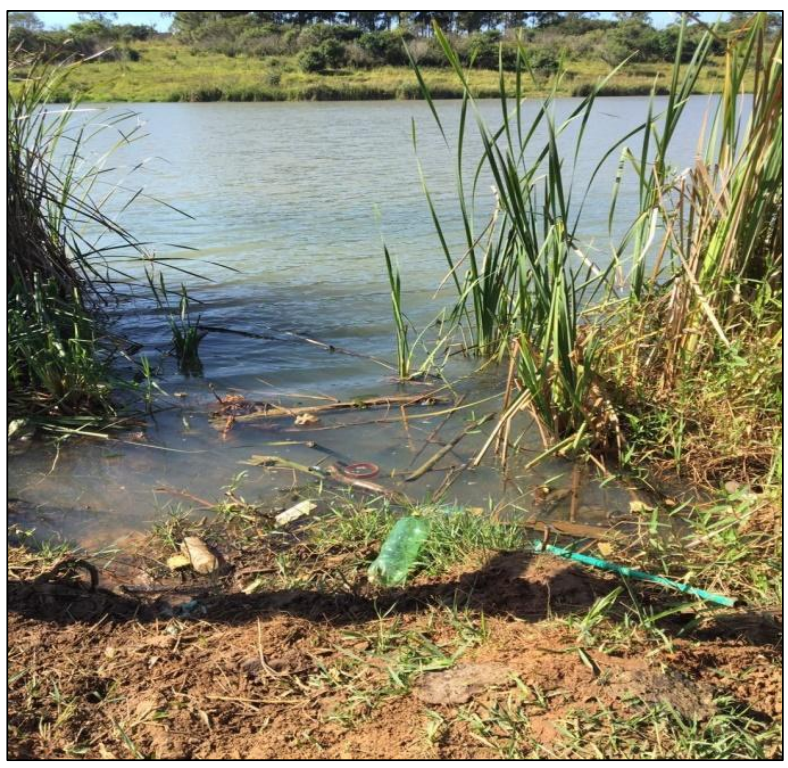

Fonte: (Autores, 2019).

A presença da taboa já foi identificada anteriormente no estudo de Soares e Leal (2015) e foi necessária a remoção da mesma para que os banhistas pudessem ter acesso à água. Entretanto, no presente estudo foi identificado a proliferação de taboas principalmente no ponto 5 (figura 11). Esse fator 
pode ter ocorrido devido ao que explica o estudo de Barboza, Franco e Hernandez (2008), em que a presença de taboas são um indicativo de que a área está degradada. Carvalho et al. (2005) também aponta que a presença dessa macrófita, designa altos índices de processo de assoreamento, sendo considerado outro fator que pode ter contribuído para o aumento da taboa.

Figura 11. Proliferação de taboa no ponto 5.

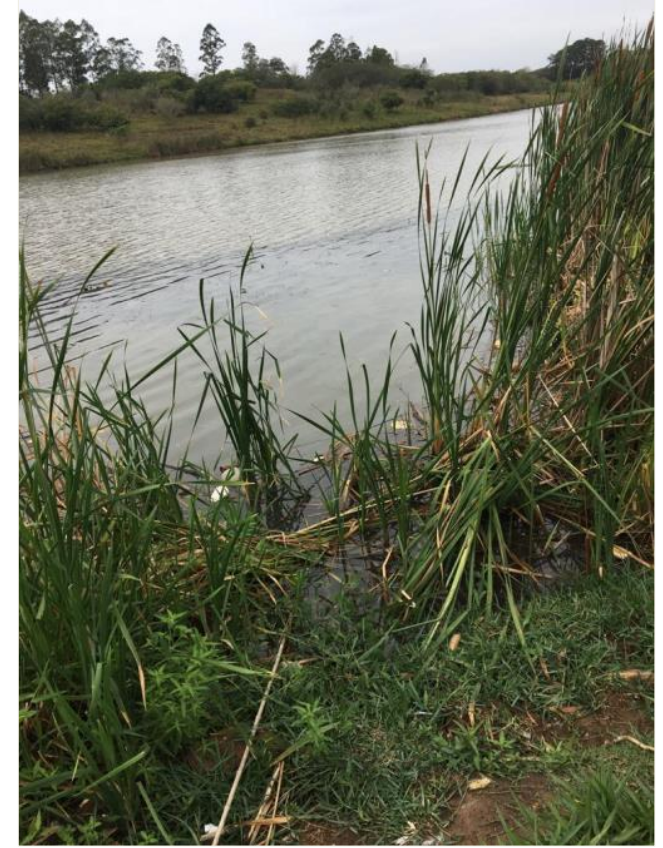

Fonte: (Autores, 2019).

$\mathrm{O}$ aspecto mais frequente durante toda a pesquisa foi o descarte irregular de resíduos sólidos. Próximo à coleta de todos os pontos, havia a presença de resíduos, sendo em maioria garrafas pet, papel e sacolas plásticas (figura 12).

Figura 12. Descarte de resíduos próximo ao ponto 4.

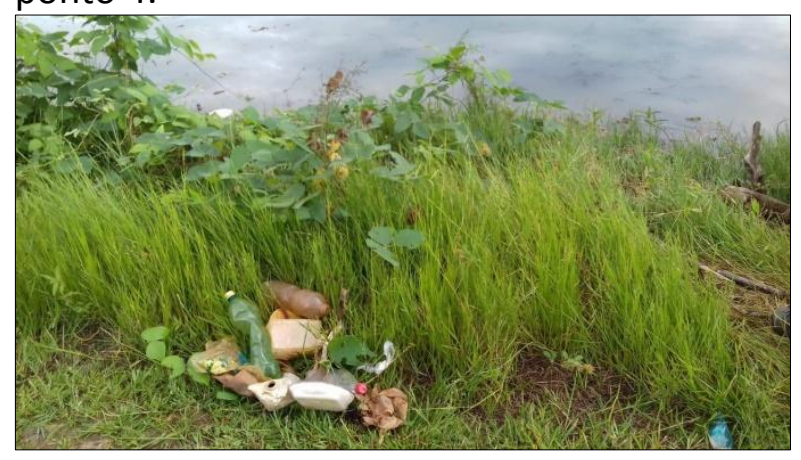

Fonte: (Autores, 2019).
Durante esse período, as árvores apresentaram aspecto seco e escura, aparentando um possível incêndio ilustrado na figura 13.

Figura 13. Aspecto da vegetação próximo aos pontos 4 e 5.

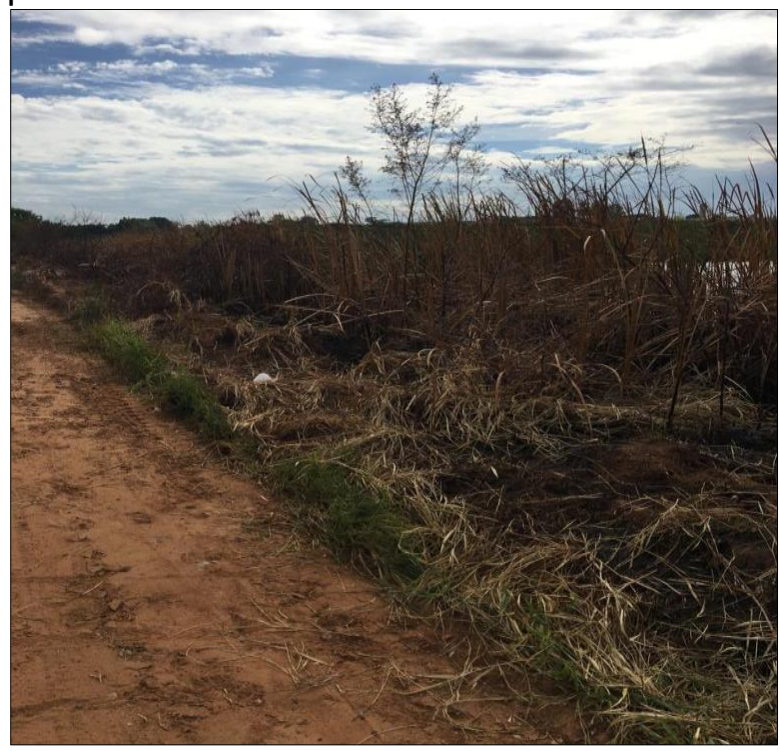

Fonte: (Autores, 2019).

Ainda no primeiro mês, em relação ao ponto 3, detectou-se intervenções na área que pertence ao município de Álvares Machado. Segundo Goulart e Callisto (2003), isso afeta de alguma maneira os ecossistemas aquáticos. Essa situação pode ter ocorrido devido ao acesso da população para as práticas de pesca e as obras que estavam sendo realizadas no entorno. No decorrer dos meses de coleta, essas interferências foram se intensificando, como ilustrado na figura $14 \mathrm{e}$ 15. 
Figura 14. Situação do ponto 3 no início da coleta.

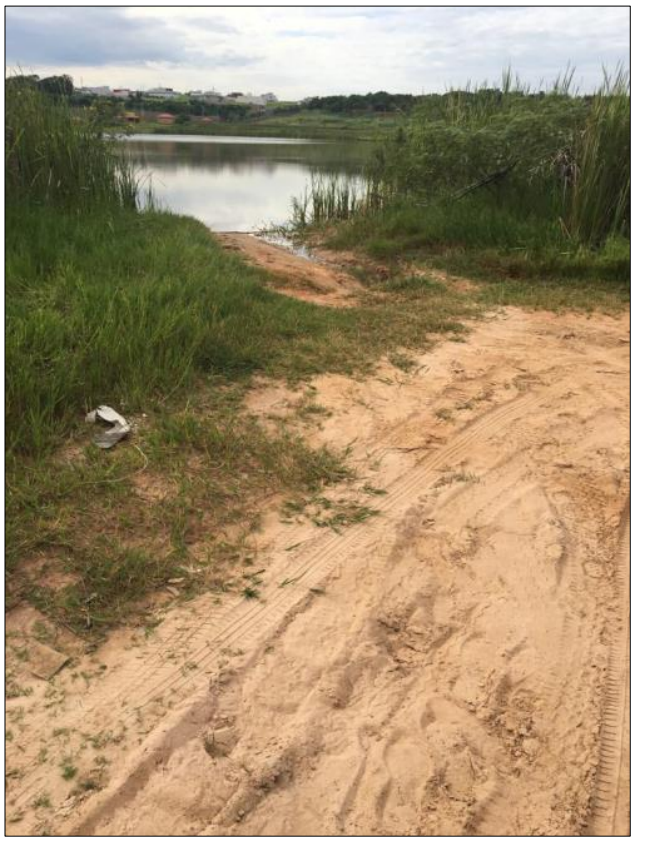

Fonte: (Autores, 2019).

Figura 15. Ponto 3 no final dos meses de coleta.

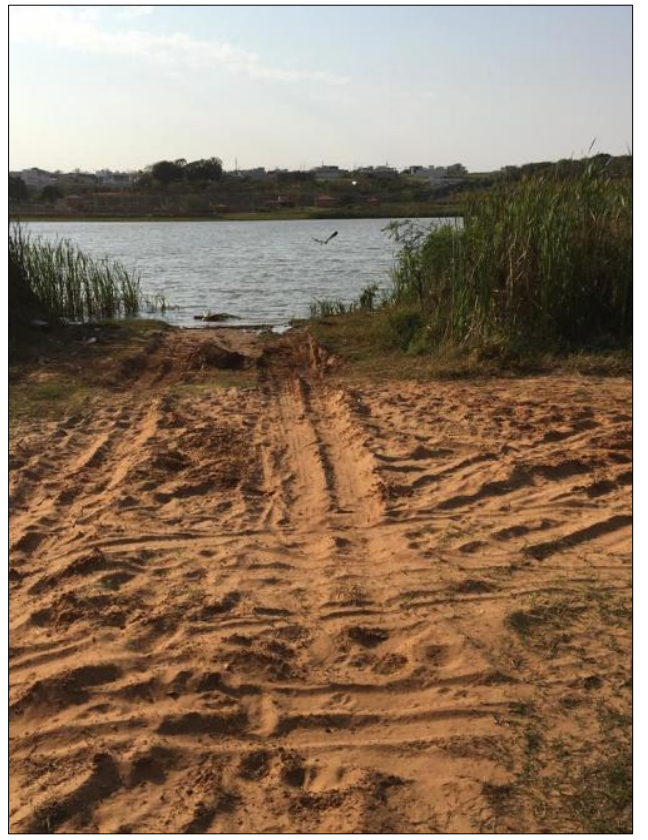

Fonte: (Autores, 2019).

No percurso de acesso ao ponto 4 e 5 , correspondente a região de Álvares Machado, notou-se que a aparência escura e aspecto seco da vegetação conforme a figura 16 , aponta ser uma possibilidade de incêndio no local. Essa prática pode ter sido ocasionada de maneira intencional ou negligente, por ações antrópicas ou de maneira natural pro- vocada pela intensidade do calor e raios solares (PORTAL AMBIENTE BRASIL, 2019).

Figura 16. Aspecto da vegetação próximo aos pontos 4 e 5.

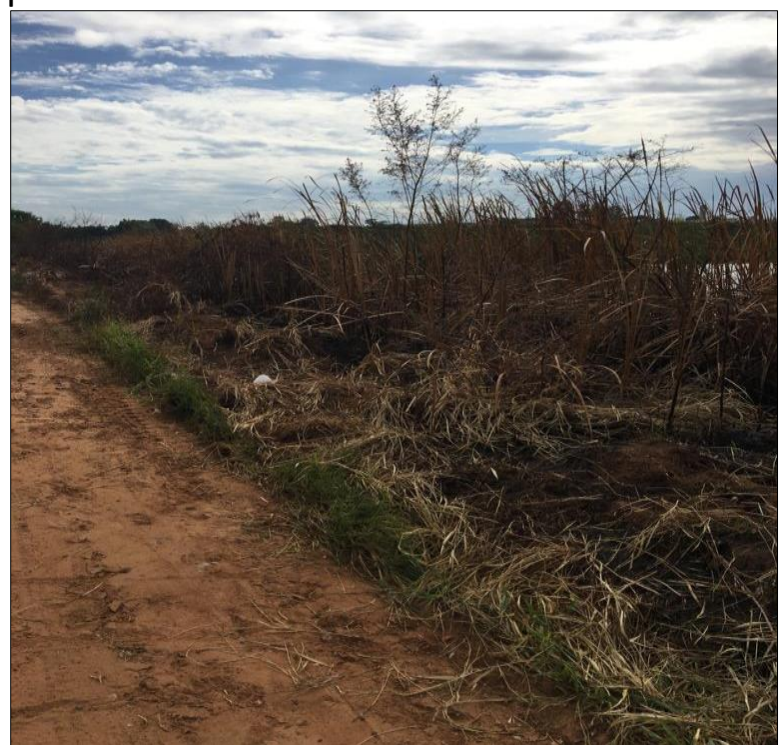

Fonte: (Autores, 2019).

Durante o trabalho de campo, outro aspecto a salientar é a presença de animais aquáticos e fezes de animais, que foram identificados na água e no solo (figura 17 e 18).

Figura 17. Patos nadando próximo ao ponto 1.

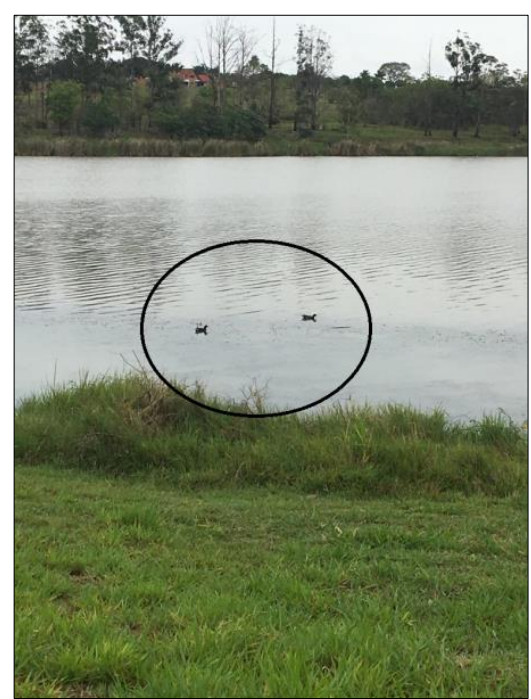

Fonte: (Autores, 2019). 
Figura 18. Fezes de capivara próximo ao ponto 1.

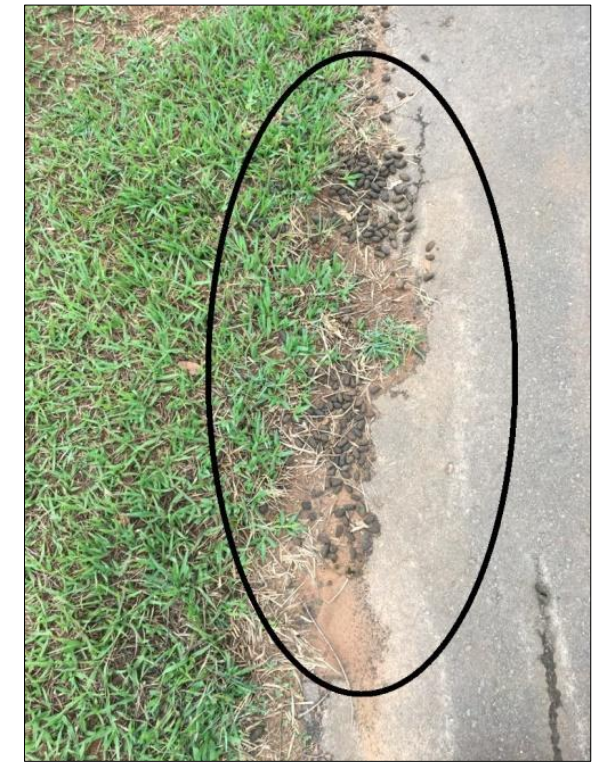

Fonte: (Autores, 2019).

No mês de setembro, notou-se a existência de girinos, principalmente no ponto 2 , sendo considerado um indicativo de qualidade de água. Juncá (2017) afirma que a presença deles indica um ambiente aquático propício conforme ilustra a figura 19.

Figura 19. Aparecimento de girinos no ponto 2.

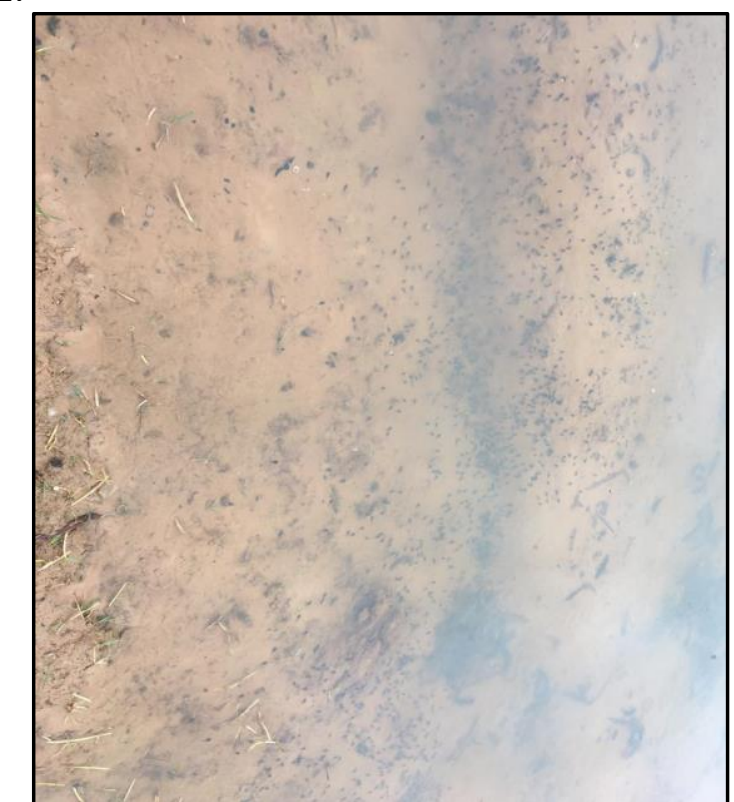

Fonte: (Autores, 2019).

Em virtude das observações e do relatório fotográfico apresentado nesse levantamento de aspectos ambientais da área de estudo, os resultados das análises podem ter sido afetados pelos elementos aqui expostos, ressaltando que podem ter ocorrido outros fatores físicos do local e que não foi possível identificá-los.

\subsection{Análise microbiológica da água e discus- são dos resultados}

Após as análises no laboratório, foi realizado a contagem das colônias conforme a figura 20.

Figura 20. Contagem de colônias em meio Ágar seletivo.

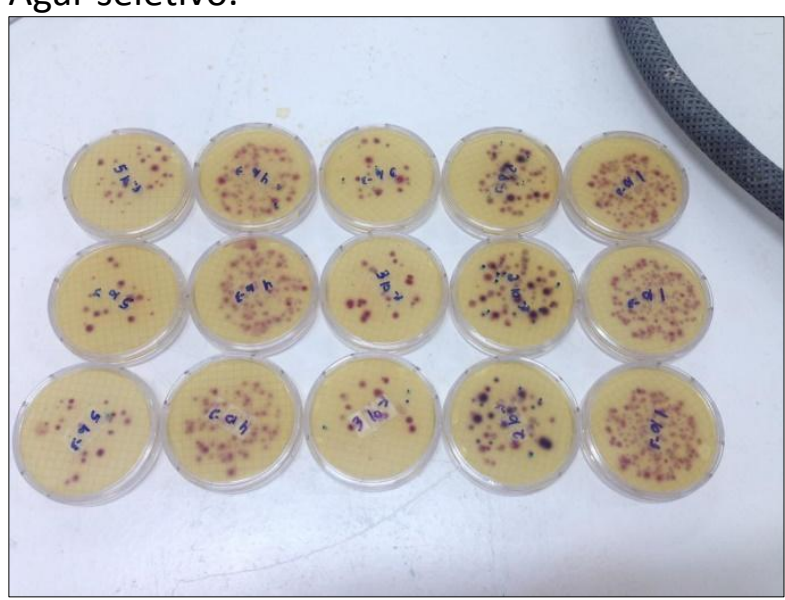

Fonte: (Autores, 2019).

Ressalta-se que um dia antes da coleta dos meses de maio e setembro houve a incidência de chuva, podendo contribuir com a diluição dos compostos, conforme aponta Queiroz, Da Silva e De Paiva (2017) em seu estudo.

Com os resultados obtidos, os mesmos foram discutidos com base na Resolução CONAMA no $274 / 2000$, que indica os limites de cada parâmetro, sendo nesse caso os valores de coliformes termotolerantes e Escherichia coli.

\subsubsection{Coliformes termotolerantes}

Considerando que acima de 2500 colônias de coliformes termotolerantes a Resolução no. 274/2000 estabelece essa água como imprópria para fins de balneabilidade, $80 \%$ dos pontos ao longo de todos os meses foram considerados impróprios.

Os valores mais acentuados foram, o ponto 4 no mês de abril, com a presença de 118.000 colônias e o ponto 1 do mês de ju- 
nho com 84.330 colônias como demonstra a

tabela 1.

Tabela 1. Resultados obtidos de coliformes termotolerantes em Unidade Formadora de Colônias (UFC).

\begin{tabular}{c|c|c|c|c|c}
\hline $\mathbf{P}$ & \multicolumn{5}{|c}{ Meses } \\
$\mathbf{0}$ & \multicolumn{5}{|c}{} \\
$\mathbf{n}$ & & & & & \\
$\mathbf{t}$ & Abr. & Maio & Jun. & Ago. & Set. \\
$\mathbf{0}$ & & & & & \\
$\mathbf{s}$ & & & & & 77.660 \\
\hline $\mathbf{1}$ & 18.000 & 660 & 84.330 & 8.660 & 83.660 \\
\hline $\mathbf{2}$ & 10.330 & 1.000 & 1.000 & 3.660 & 21.330 \\
\hline $\mathbf{3}$ & 1.000 & 660 & 5.330 & 4.000 & 9.330 \\
\hline $\mathbf{4}$ & 118.000 & 4.000 & 38.330 & 1.660 & \\
\hline $\mathbf{5}$ & 5.660 & 4.330 & 12.330 & 9.660 & 28.000 \\
\hline
\end{tabular}

Fonte: (Autores, 2019).

Levando em consideração o ponto 2, onde é destinado para os banhistas, no mês de setembro o ponto atingiu 83.660 colônias. Nesse mês, o mesmo demonstrou maior presença de colônias em relação aos outros pontos. Apesar de não ter sido o maior resultado encontrado nas análises em relação a todos os meses, a resolução explica que a classificação deve ser feita com base na última amostra. Em virtude disso verificou-se que a qualidade nesse ponto estava imprópria.

Em estudos realizados anteriormente por Soares e Leal (2015), o resultado foi divergente por ter sido classificada como excelente. Nota-se dessa maneira que ao longo dos anos intensificou a presença de microorganismos termotolerantes.

Essa classe de micro-organismos está presente em fezes humanas e de animais, da qual foi demonstrado nos aspectos ambientais da área ao identificar a presença de patos no local e fezes de capivara.
Leser et al. (1985) aponta que a ocorrência de coliformes em água pode contribuir para a proliferação de doenças de veiculação hídrica. Além disso, a abundância de coliformes termotolerantes também pode estar relacionada ao lançamento de efluentes que contenham matéria orgânica, conforme define a resolução CONAMA no. 274/2000.

\subsubsection{Escherichia coli}

Tratando-se das colônias de E. coli na tabela 2, percebe-se um crescimento ao longo dos meses e um pico na quantidade de colônias no mês de julho, referente ao ponto 2 , e em agosto, no ponto 5. Em alguns meses, não houve a presença desse grupo de coliformes, como pode ser observado nos meses de abril, maio, junho e agosto. O único mês com a presença de colônias em todos os pontos foi em setembro. 
Tabela 2. Resultados obtidos da análise de água e identificação da bactéria E. coli em Unidade Formadora de Colônias (UFC).

\begin{tabular}{l|c|c|c|c|c}
\hline \multirow{2}{*}{ Pontos } & \multicolumn{5}{|c}{ Meses } \\
\cline { 2 - 6 } & Abr. & Maio & Jun. & Ago. & Set. \\
\hline $\mathbf{1}$ & 660 & 330 & - & - & 3.000 \\
\hline $\mathbf{2}$ & - & - & 12.330 & 2.330 & 1.000 \\
\hline $\mathbf{3}$ & - & - & 660 & 2.000 & 1.000 \\
\hline $\mathbf{4}$ & - & 330 & 660 & - & 330 \\
\hline $\mathbf{5}$ & 660 & - & 330 & 9.660 & 330 \\
\hline
\end{tabular}

- Não identificado colônias na membrana filtrante.

Fonte: (Autores, 2019)

Para o parâmetro de E. coli, a Resolução Conama no 274/2000 estabelece como critérios destinados para avaliar a balneabilidade (recreação primário) a quantidade limite de 2000 colônias. Diante disso, os resultados que ultrapassou essa classificação foi o ponto 2 no mês de junho e agosto, o ponto 5 no mês de agosto e o ponto 1 no mês de setembro.

Uma possível hipótese para o excesso de E. coli foi identificada no levantamento de aspectos ambientais, com a presença de fezes de animal encontrada no solo e na água. Outra hipótese para o aumento das colônias ao longo dos meses é que alguma tubulação de esgoto doméstico tenha sido prejudicada e esteja ocorrendo o despejo de forma inadequada.

Referente ao ponto 2, local destinado exclusivamente aos banhistas, no mês de setembro foi identificada a presença de 1000 colônias, atendendo a Resolução CONAMA no 274/2000. Levando em consideração o mesmo mês e ponto, além da questão do indicador microbiológico mais restritivo, ao comparar o resultado de E. coli e coliformes termotolerantes, nota-se que a presença de 83.660 coliformes termotolerantes restringe $\mathrm{o}$ uso para contato primário nesse local.

Em contrapartida, Soares e Leal (2015) analisou a balneabilidade através de outro trecho da resolução e utilizou o parâmetro de colônias de E. coli. A conclusão do estudo foi que a água estava atendendo os parâmetros de balneabilidade.

\section{CONSIDERAÇÕES FINAIS}

Considerando os meses de coleta, verificou-se uma variação significativa entre um mês e outro, podendo ter sido ocasionado por fatores antrópicos, bióticos e abióticos identificados no levantamento de aspectos ambientais da área de estudo. Com base nos resultados dos parâmetros microbiológicos, foi possível identificar que a água não atende ao estabelecido na Resolução CONAMA no 274/2000 para os parâmetros de balneabilidade, levando em consideração o indicador microbiológico mais restritivo, o Coliforme termotolerante. Sendo assim, conclui-se que a qualidade da água do Balneário da Amizade não se encontra apta para fins de uso primário. Dessa maneira, é necessário o monitoramento da qualidade da água de forma contínua e implementação de melhorias, principalmente pelo fato de que os aspectos ambientais contribuíram para a alteração da qualidade da água.

\section{AGRADECIMENTOS}

Agradecemos a todos os colaboradores desse trabalho, principalmente ao orientador e ao técnico do laboratório da Universidade do Oeste Paulista que deram todo o apoio para que esse trabalho fosse realizado com êxito.

\section{REFERÊNCIAS}

AMERICAN PUBLIC HEALTH ASSOCITION. Standard Methods for The Examination ofWater \& Wastewater - 21st Edition. Washington:APHA, 2005. 
BARBOZA, G. C.; FRANCO, R. A. M.; HERNANDEZ, F. B. T. Ocorrência de macrófitas aquáticas no córrego do boi. In: WORSHOP INTERNACIONAL DE INOVAÇÕES TECNOLOGIAS NA IRRIGAÇÃO, 2., SIMPÓSIO BRASILEIRO SOBRE O USO MÚLTIPLO DA ÁGUA, FORTALEZA - CE, 1. p. 680-686, jun. 2008. Disponível em: <https://www2.feis.unesp.br/irrigac ao/pdf/winotec2008_artigo_gustavo.pdf>. Acesso em: 20 nov. 2019.

BRASIL. Agência Nacional de águas. Usos de água. Disponível em: $<$ https://www.ana.gov.br/u sos-da-agua/outros-usos>. Acesso em: 09 out. 2019.

BRASIL. Lei no 6938, de 31 de agosto de 1981. Dispõe sobre a Política Nacional do Meio Ambiente, seus fins e mecanismos de formulação e aplicação, e dá outras providências. Diário Oficial da União, Brasília, DF, 31 ago. 1981. Disponível em:

$<$ http://www.planalto.gov.br/ccivil_ 03/LEIS/L6938compilada.htm>. Acesso em: 15 jul. 2020.

BRASIL. Lei no 9433, de 8 de janeiro de 1977. Institui a Política Nacional de Recursos Hídricos, cria o Sistema Nacional de Gerenciamento de Recursos Hídricos, regulamenta o inciso XIX do art. 21 da Constituição Federal, e altera o art. 10 da Lei $\mathrm{n} 08.001$, de 13 de março de 1990, que modificou a Lei no 7.990, de 28 de dezembro de 1989. Diário Oficial da União, Brasília, DF, 8 jan. 1997. Disponível em: <http://www.planalto.gov. br/ccivil_03/LEIS/L9433.htm>. Acesso em: 15 jul. 2020.

BRASIL. Resolução CONAMA no 274, de 20 de novembro de 2000 . Revisa os critérios de Balneabilidade em Águas Brasileiras. Diário Ofical da União, Brasília, DF, 25 jan. 2001. Disponível em: <http://www2.mma.gov.br/port/conama/leg iabre.cfm?codlegi=272>. Acesso em: $10 \mathrm{abr}$. 2019.
CARVALHO, F. T. et al. Influência da Turbidez da Água do Rio Tietê na ocorrência de plantas aquáticas. Planta Daninha, Viçosa - MG, v. 23, n.2, p. 359-362, ago. 2005. Disponível em: $<$ https:// doi.org/10.1590/S010083582005000200025 >Acesso em: 20 nov. 2019. https://doi.org/10.1590/S0100$\underline{83582005000200025}$

FROIS, M. R. Problemas ambientais provocados pela extensão urbana na bacia do Córrego do Limoeiro em Presidente Prudente SP. 2015. Dissertação (Mestrado em Ciências Ambientais) - Universidade do Oeste Paulista, Presidente Prudente, 2015. https://doi.org/10.17271/231884723182015 1024

GOULART, M. D.; CALLISTO, M. Bioindicadores de qualidade de água como ferramenta em estudos de impacto ambiental. Revista da FAPAM, v. 2, n. 1, p. 156-164, 2003. Disponível em:

$<$ http://www.urisan.tche.br/ briseidy/P\%F3 s\%20Licenciamento\%20Ambiental/bioindicad ores\%2019.10.2010.pdf>. Acesso em: 01 out. 2019.

JUNCÁ, F. A. et al. Girinos como indicadores da qualidade da água do Rio Doce. 2017. Greenpeace. Disponível em:< https://www.green peace.org.br/hubfs/Campanhas/Agua_Para_Que $\mathrm{m}$

/documentos/GP_girinosbioindicadoresRioD oce.pdf>. Acesso em: 19 nov. 2019.

LESER, W. S. et al. Elementos de epidemiologia geral. São Paulo: Atheneu, 1985.

SELBORNE, L. A ética do uso da água doce: um levantamento. Brasília: UNESCO, 2001.

PORTAL AMBIENTE BRASIL. Queimadas, incêndios florestais. Disponível em: <https:// ambietes.ambientebrasil.com.br/florestal/ arti- 
gos/queimadas_incendios_florestais.html>. Acesso em: 10 out. 2019.

QUEIROZ, L. G.; DA SILVA, F. T.; DE PAIVA, T. C. B. Caracterização estacional das variáveis físicas, químicas, biológicas e ecotoxicológicas em um trecho do Rio Paraíba do Sul, SP, Brasil. Ambiente \& Água-An Interdisciplinary Journal of Applied Science, Taubaté, v. 12, n. 2, p. 238-248, abr. 2017. Disponível em: $<$ https://www. scielo.br/pdf/ambiagua/v12n2/1980-993Xambiagua-12-02-00238.pdf. Acesso em: 28 out. 2019. https://doi.org/10.4136/ambiagua.1949

SOARES, F. B; LEAL, A. C. Planejamento e zoneamento ambiental da bacia hidrográfica do manancial Balneário da Amizade nos municípios de Álvares Machado e Presidente Prudente - São Paulo/ Brasil. 2015. $230 \mathrm{f}$. Dissertação (Mestrado) - Universidade Estadual Paulista, Faculdade de Ciências e Tecnologia, 2015. Disponível em:https:

<//repositorio.unesp.br/ handle/11449/136010>. Acesso em: 15 jul. 2020.

SPERLING, M. V. Introdução à qualidade das águas e ao tratamento de esgotos. 3. ed. Belo Horizonte: Departamento de Engenharia Sanitária e Ambiental, Universidade Federal de Minas Gerais, 2005. 